\title{
BUNSEN FLAMES OF UNUSUAL STRUCTURE
}

\author{
By Francis A. Smith and S. F. Pickering
}

\section{ABSTRACT}

A mixture of air or oxygen with a combustible gas is forced through a cylindrical burner tube, and the flame is observed as it burns in secondary air.

Complex structures observed in acetylene-air flames include the intersection of two zones, four distinct zones of light, and a hollow dark core extending upward from the tip of the primary zone.

When secondary air is excluded, the primary zones of some hydrocarbon-air flames become polyhedral. Flames having 3, 4, 5, 6, and 7 sides have been observed, which will rotate under some conditions and remain stationary under others. The number of sides is a function of the size of the burner tube and of the composition of the gas mixture.

Burning in secondary air under some conditions, the primary zone of a propane-oxygen flame becomes polyhedral, and yellow streamers rise from the tip and corners of the figure, which can be made to rotate slowly, or rapidly, or to remain stationary, by slight changes of the composition and velocity of the mixture of gas and oxygen supplied to the burner.

Accurate and reproducible control of the composition and rate of flow of the gas mixtures and very steady streamline flow in the burner tubes have been attained.

Twenty photographs of the above flames are presented and discussed.

\section{CONTENTS}

I. Introduction

II. Description of the flames .

1. Polyhedral primary zone

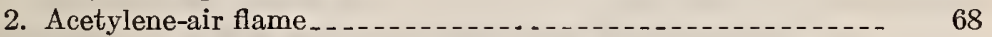

3. Some interesting propane-oxygen flames.... 70

III. Discussion_......... 71

1. Variables which affect the polyhedral primary zone _..... 71

2. A possible cause of rotation of the polyhedral figure._._._. $\quad 73$

3. Points of similarity and of contrast between the flames..... 73

\section{INTRODUCTION}

Certain phases of the physics and chemistry of flames are being studied for quite different purposes in more than one laboratory at the Bureau of Standards. The work of the present authors has for its primary object the improvement of combustion in gas burners.

In order to determine the conditions governing flash back and blow-off in burners, and to obtain a better understanding of the mechanism of flame propagation and of the relative importance of 
the many factors involved, measurements of the flame velocities in a number of gas mixtures have been made.

The method employed was essentially that described by Bunsen, ${ }^{1}$. Gouy, ${ }^{2}$ Michelson, ${ }^{3}$ Hofsäss, ${ }^{4}$ Mache,${ }^{5}$ and others, modified in certain respects by $\mathrm{F}$. W. Stevens, ${ }^{6}$ and also by the authors. ${ }^{7}$.

In the present connection it will be sufficient to say that accurate and reproducible control of the velocity and composition of the gas mixtures was attained by means of needle valves and flow meters, one set of which controlled the gas supply, and the other set the supply of primary air or oxygen. The homogeneous mixture flowed out through a vertical burner tube, the inner surface of which was made as smooth and as nearly cylindrical as possible, and burned in the presence of the surrounding secondary air. The flame which usually results is the ordinary Bunsen flame which has been described essentially as follows:

A Bunsen flame has three chemically distinct parts. The inner cone is a very thin greenish blue zone where the oxygen of the air supplied to the burner is consumed and the combustible components of the fuel gas are oxidized to a mixture of $\mathrm{CO}, \mathrm{CO}_{2}, \mathrm{H}_{2}$, and $\mathrm{H}_{2} \mathrm{O}$. Combustion is completed to $\mathrm{CO}_{2}$ and $\mathrm{H}_{2} \mathrm{O}$ by outside air in a thin reaction zone surrounding the flame, and called the outer cone. The space between the two cones (called the water-gas space) is practically free from chemical processes.

In the course of this work several phenomena of a rather unusual nature have been encountered. Many of them have not been previously reported, and are sufficiently interesting to justify publication on their own account, even though their causes have not yet been determined.

It has been found necessary to alter the significance of some of the terms used to describe some parts of the flame, and in some cases to substitute a different term for one frequently used to avoid ambiguity when discussing the flames to be described. For instance, the word "zone" is substituted for "cone" because none of the zones is really a true cone, especially when the base is a regular polygon. The term "primary zone" refers to that part of a flame usually called the "inner cone" and is used because it is the seat of the initial or primary combustion, and because it is no longer necessarily the only inner zone. The term "mantle" designates the part or parts of a flame which are outside the primary zone. The term "envelope" is

1 Bunsen, Pogg. Ann., 131, p. 161; 1866.

2 Gouy, Ann. Chim. Phys. (5), 18, p. 27; 1879.

8 Michelson, Ann. Phys. (3), 37, p. 1; 1889.

- Hofsäss, Chem, Ztg., 39, p. 64; 1915.

- Mache, Die Physik der Verbrennungserscheinungen, Leipzig; 1918.

F. W. Stevens, National Advisory Committee on Aeronautics, Rept. No. 305; 1929.

${ }^{7}$ Investigation still in progress. 
substituted for the terms "outer cone" or "mantle" as commonly used and designates that very thin outer portion of the mantle in which combustion is completed by means of outside or secondary air.

\section{DESCRIPTION OF THE FLAMES}

\section{POLYHEDRAL PRIMARY ZONE}

At one stage of the work on measurements of flame velocity it became necessary to determine whether or not the primary zone was affected in any way by the zone of secondary combustion which ordinarily surrounds it. A Smithells' flame separator ${ }^{8} \mathrm{was}$, therefore, used to exclude secondary air. Under the conditions of the original experiment, using propane and air, when secondary air is excluded the primary zone or combustion surface presents the appearance shown in Figure 1.

In form it is very much like a tent supported by five ropes loosely draped from a center pole to pegs located at the corners of a regular pentagon. It is perfectly stable and reproducible. The phenomenon appeared so interesting that some other gas mixtures and burners of several sizes were tried in an effort to determine its cause. Several combinations were found which gave polyhedral fiames of the same general character as those photographed. The length of a side at the base seems to be a characteristic of the gas mixture used. In the case of propane and air it averages about $6 \mathrm{~mm}$, and by using larger or smaller burners figures having a larger or smaller number of sides are obtained. In this way, flames having $3,4,5,6$, and 7 sides have been observed. If the circumference of the burner is about the mean of the dimensions which give stable four-sided or five-sided figures, either may be obtained on the same burner by varying the composition of the mixture slightly. The figure can be made to rotate rapidly or slowly, or to remain stationary, by changing very slightly the composition and velocity of the gas mixture.

For example, in the case of a burner tube made of glass and having a diameter of $7.3 \mathrm{~mm}$, a mixture containing 5.06 per cent of propane in air produced the usual circular "cone." An increase in the proportion of propane caused the figure to change to a rounded, steady, four-sided figure which became sharper, then somewhat unsteady, then changed to an unsteady five-sided figure, and finally broke into rapid rotation, at which time the mixture contained 5.47 per cent of propane, an increase of only 0.41 per cent.

This polyhedral primary zone, while unusual, is not new. Smithells and Ingle ${ }^{9}$ briefly described a flame which must have been very similar to this one.

${ }^{8}$ Smithells and Ingle, J. Chem. Soc., 61, p. 207; 1892. A glass tube of larger diameter than the burner tube is attached air-tight to the latter a little below the tip. It extends upward above the tip of the burner tube and completely excludes outside air from the primary zone. The gases from the primary zone then burn at the tip of the larger tube.

- See footnote 8. 


\section{ACETYLENE-AIR FLAME}

When work was begun with acetylene-air mixtures, with the flame burning in secondary air in the usual manner, it was immediately evident that the structure of some acetylene flames is much more complex than that of Bunsen flames is ordinarily supposed to be.

The following figures show some of this structure in successive stages of development as the proportion of acetylene is increased:

Figure 2 shows the primary zone with very little mantle. The mixture (5.1 per cent $\mathrm{C}_{2} \mathrm{H}_{2}$ ) is almost as lean as it can be without the flame blowing off. This mixture contains 56 per cent more primary air than that required for the complete combustion of the acetylene. The excess of air either furnishes a sufficient concentration of oxygen to enable the reactions to go to completion in the primary zone, or by diluting with nitrogen so reduces the temperature of the gases leaving the primary combustion zone that no further reaction is apparent.

Figure 3 (11.7 per cent $\mathrm{C}_{2} \mathrm{H}_{2}$ ) shows much more mantle. This mantle is not a hollow shell as is usually the case, but extends inward all the way to the primary zone.

While a consideration of the greater depth through which the center of the flame is viewed, as compared with the edges, shows that the region near the outer boundary produces much more light than that toward the center, it is obvious that in this flame the emission of light is not confined to the envelope. Furthermore, flames having fairly large mantles result from mixtures approaching that used to obtain Figure 2, and in these flames the intensity of the light appears to the eye actually to increase from the boundary toward the center. In view of this fact, it seemed probable that the exclusion of secondary air by means of a Smithells' flame separator would not result in removing this mantle from about the primary zone. The experiment was tried and no difference in the appearance of the flame could be detected as a result of the exclusion of secondary air from the flame last described.

These facts indicate that some reaction is in progress, after the gases have passed the primary zone, which does not depend upon the presence of secondary air. The sharp outer boundary of the primary zone indicates that the reactions in the two regions are not of the same character, otherwise the primary zone would blend gradually into the region above.

Figure 4 shows the mantle with its usual hollow appearance (more clearly shown in fig. 5) only partly developed. This mixture (13.2 per cent $\mathrm{C}_{2} \mathrm{H}_{2}$ ) contains as primary air 55 per cent of the air required for the complete combustion of the acetylene and the remainder must come from the secondary air which surrounds the flame. Most of the light from this mantle comes from its envelope. 
B. S. Journal of Research, RP84

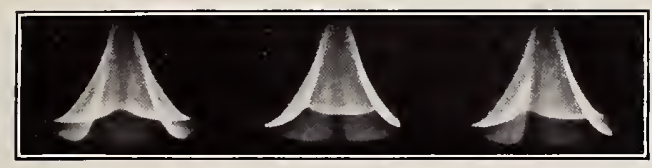

Figure 1

Pentahedral propane-air flames

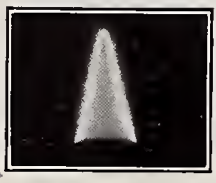

Figure 2

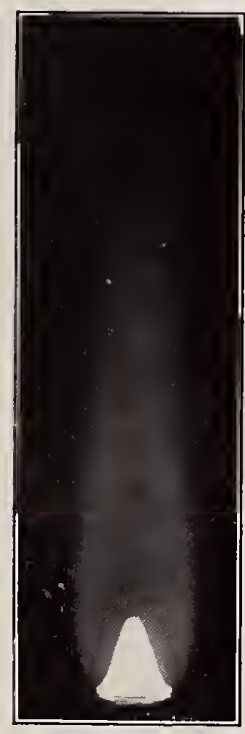

FIGURE 3

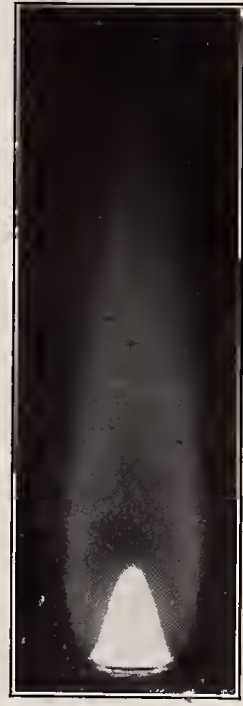

FIGURE 4

Acetylene-air flames

$68-1$ 


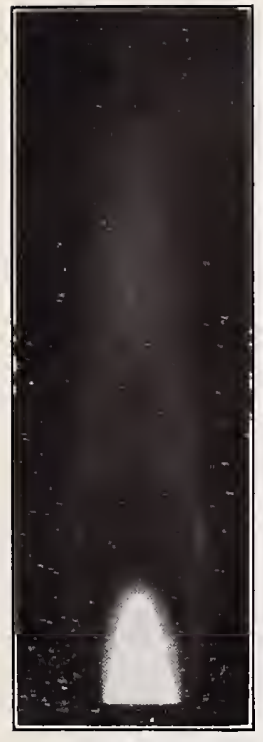

FIGURE 5

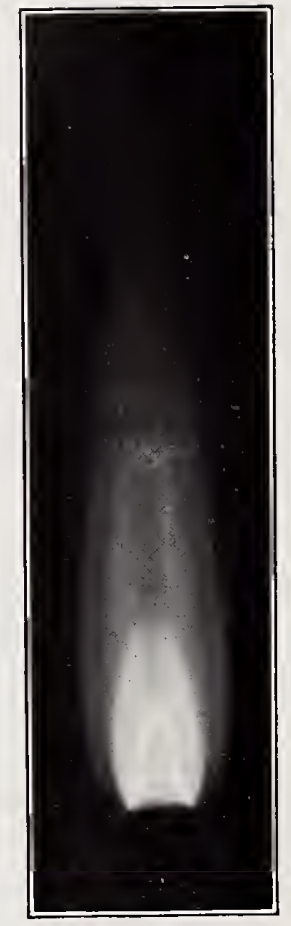

Figure 7

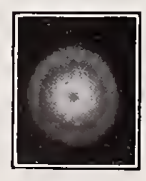

FIGLRE 8

Acetylene-air flames

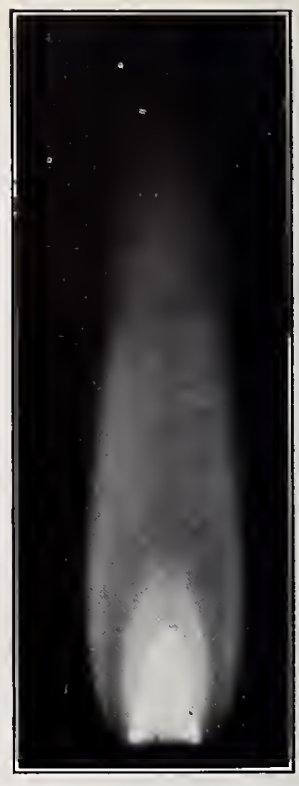

Figure 6 
B. S. Journal of Research, P.P\&4

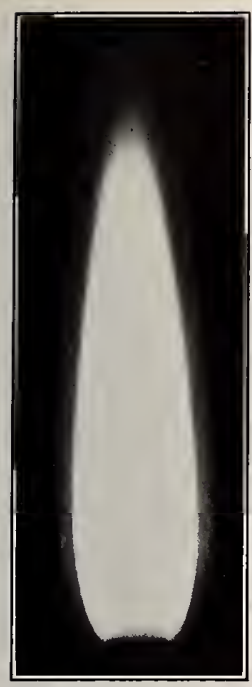

Figure 9

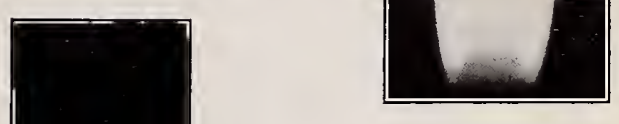

FIGURE 10

FIgURE 11

Acetylene-air flames 
Figure 5 (15.6 per cent $\mathrm{C}_{2} \mathrm{H}_{2}$ ) shows a second inner zone which emits light containing more yellow than that from the pale bluegreen primary zone. This zone is shaped like a thimble and has no sharply defined boundary except near its base which extends to a somewhat lower level than the base of the primary zone and is considerably larger in diameter than the latter. The base of the primary zone is itself much larger in diameter than the tip of the burner tube and begins some distance above it.

In Figure 6 (16.3 per cent $\mathrm{C}_{2} \mathrm{H}_{2}$ ) the upper portion of the second zone is much larger, its base remaining about the same. A third inner zone has appeared, the base of which is located on the surface of the primary zone at or slightly above its base. It extends outward and upward until it crosses the boundary of the second inner zone, and that portion of it which is inside zone 2 begins to show the yellow color characteristic of flames commonly called "luminous." This color makes the outer boundary of zone 2 much more distinct. That portion of zone 3 which is outside of zone 2 is as yet scarcely visible.

In Figure 7 ( 16.6 per cent $\mathrm{C}_{2} \mathrm{H}_{2}$ ) the yellow third zone is entirely distinct. Starting at the base of the primary zone it occupies most of the second zone, intersects it, and extends outside it. The primary zone and the second and third inner zones are each surrounded by a thin space which appears dark. These dark spaces join at their tips in a continuous dark streak which extends from the tip of the primary zone upward through the center of the flame. Viewed from above, as shown in Figure 8, the streak is obviously a hollow, dark central core, and the spaces appear as rings of darkness surrounding and separating the zones of light.

In Figure 9 (17.7 per cent $\mathrm{C}_{2} \mathrm{H}_{2}$ ) the brilliance of the second and third inner zones has increased and the line of separation between them is no longer visible except at the base where that portion of zone 2 not occupied by zone 3 is still green. The dark core is still perceptible near the tip and the dark space separating zone 3 from the blue envelope is still clearly visible.

Zones 2 and 3 in Figure 10 (24.0 per cent $\left.\mathrm{C}_{2} \mathrm{H}_{2}\right)$ have increased in size and brilliance until they occupy nearly the entire volume of the flame. Although it is invisible until the eye has been shielded from the brilliance of the central portion of the flame a continuous blue envelope may then be seen which incloses the rest of the flame completely.

Figure 11 (44.8 per cent $\mathrm{C}_{2} \mathrm{H}_{2}$ ) shows the brilliance of all parts of the flame greatly reduced for lack of primary air. That which was the primary zone now appears merely as a brighter region in the yellow portion of the flame. The boundary of the yellow portion of this flame is exceedingly sharp. Above the primary zone at least it is a very thin and brilliant sheath, the edge of which appears on the 
photograph as a sharply drawn white line shading toward the center. Just outside this line is a thin dark space which distinctly separates the yellow zone from the thin blue envelope which now can be seen plainly at the sides. This blue envelope no longer incloses the tip of the flame and unburned carbon is escaping freely at the top.

\section{SOME INTERESTING PROPANE-OXYGEN FLAMES}

Figures 12 to 17 show some of the flame structures which occur with mixtures of propane and oxygen as the proportion of oxygen is increased. These flames have a brilliant yellow stream rising from the tip of the primary zone instead of the hollow dark core of the acetylene flames.

In some of the photographs, such as Figurcs 12, 14, 16, 18, and 19, a departure was made from usual photographic practice in order to show structure which would otherwise have been obscured on account of the great differences in the intensity of the light from different parts of the flame. In these cases the plate was reversed so that the light passed through the glass before striking the emulsion, permitting the "denser" portions of the negative (in which the silver was reduced in the emulsion through its entire thickness to the outer surface) to be bleached considerably without affecting the "thinner" portions of the negative appreciably. ${ }^{10}$

Figure 12 shows a flame which results from a primary mixture containing 33.7 per cent propane in oxygen. It has a fairly welldefined primary zone surrounded by a diffuse yellow zone and the brilliant strcam rising from the tip. The entire flame is surrounded by a blue envelope.

In Figure 13 (33.4 per cent $\mathrm{C}_{3} \mathrm{H}_{8}$ ) the "cone" has become a foursided figure, and the diffuse yellow zone has separated and concentrated into four streams which rise along the dark ridges of the bluegreen primary zone. This view, facing one side of the primary figure, shows the dark ridges from which little or no light is coming, the figure consisting of four apparently disconnected sides. The cnvelope, which is invisible because of the relatively small intensity of its light, is shown clearly in Figure 14, which is a photograph of the same flame taken with the plate reversed.

Figure 15 is a diagonal view of the same flame, in which faint yellow zones resembling zones 2 and 3 of the acetylene flame are visible. The envelope, which is almost invisible, is shown clearly in Figure 16, which, however, does not show the zones just referred to very distinctly.

\footnotetext{
10 The authors are indebted to W. S. Rice, of the photographic section of this bureau, who made the photographs reproduced in this paper as well as an excellent set of autochrome photographs of the same flames.'
} 
B. S. Journal of Research, RP84

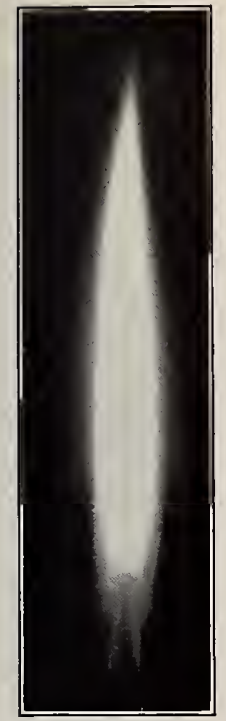

Figure 12

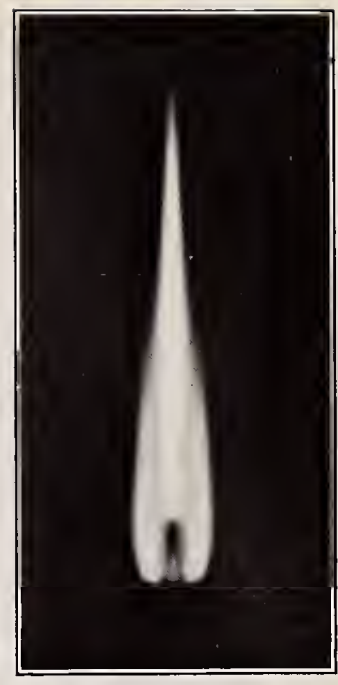

Figure 13

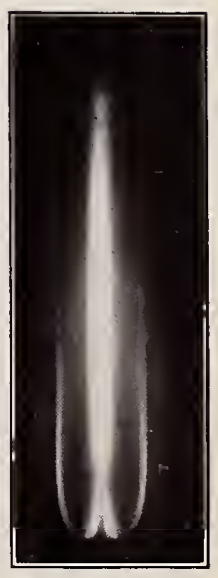

FIGURE 16

FIgURE 15

Propane-oxygen flames

ic-1 
B. S. Journal of Research, RP84

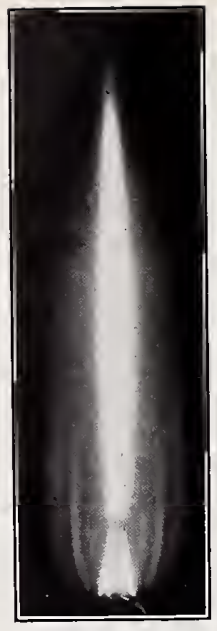

FIGURE 18

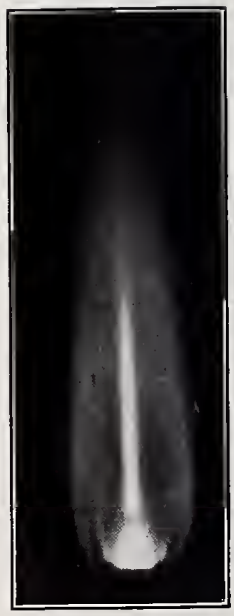

Figure 20

FIGUPE 17

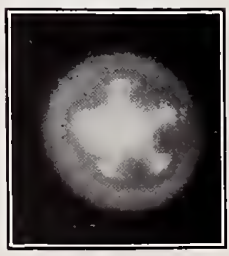

Figure 19

Propane-oxygen flames 
Figure 17 (33.0 per cent $\mathrm{C}_{3} \mathrm{H}_{8}$ ) shows the four-sided figure changed into one having five sides. The yellow streams are smaller and rise from the corners of the base instead of all along the ridges. This view shows the yellow streams and the primary figure with reasonable clarity, but the envelope is very indistinct. Figure 18 shows the various parts of the flame in their proper relative proportions, but the details are less distinct.

Figure 19 is a view of the same flame from above. The line of vision departs slightly from the vertical allowing two of the dark ridges of the primary zone to be seen at one side of the brilliant yellow stream which rises from the tip. The primary zone and the yellow streams are enveloped in a region of darkness which in turn is surrounded by the usual blue envelope.

A little more oxygen causes the figure to begin rotating slowly and still more causes very rapid rotation, shown in Figure 20 (32.2 per cent $\mathrm{C}_{3} \mathrm{H}_{8}$ ), with the yellow streams, which are now much smaller, forming an apparently continuous ring at the base and extending upward like the sides of a cup.

\section{DISCUSSION}

\section{VARIABLES WHICH AFFECT THE POLYHEDRAL PRIMARY ZONE}

There are several factors which affect the formation or behavior of the polyhedral primary zone, but apparently changes in such variables as the length and material of the burner tube, length and diameter of the separator tube which excludes secondary air, and the position of the burner and separator tube assembly have little or no effect. In the case of the latter variable the assembly was connected flexibly to the supply of primary mixture, and gradually inverted with no apparent effect upon the flame.

On the other hand, such variables as the velocity of the primary mixture through the burner tube, the diameter and shape of the tip of the burner tube, the composition of the primary mixture, the identity of the combustible gas, and the presence or absence of nitrogen in the primary mixture, affect the polyhedral figure in various ways.

Of these variables, the last three affect the velocity of propagation of the flame, and this in relation to the first two, determines in a general way the size and shape of the primary zone.

One may consider the primary zone as the resultant of two opposing tendencies. In the normal operation of a burner the velocity of the primary mixture prevents the flame from entering the burner tube and "flashing back," and at the same time the velocity of propagation of the flame enables the latter to maintain its continuity and position at the tip of the burner against the tendency of the primary mixture to "blow it off." 
Ordinarily the resulting figure approximates a right circular cone whose dimensions depend upon the relative values of the flame velocity, mixture velocity, and burner diameter.

The polyhedral figures presented in this paper and their observed behavior would seem to indicate that there are limiting values of the ratio of flame velocity to mixture velocity, and of each of those two variables, between which a figure with a circular section is less stable than one having concave sides separated by ridges spaced symmetrically around the circumference.

The distance between ridges measured along a side at the base varies with either the mixture velocity, flame velocity (or one or more of the factors which affect flame velocity), or with some combination of these variables.

The statement, previously made, that the length of a side is a characteristic of the gas mixture, is based upon the following facts. A small change in the composition of a mixture of propane and air, or of propane and oxygen suffices to change the number of sides of the figure from four to five or vice versa. The length of a side with propane-air mixtures is about $6.0 \mathrm{~mm}$, with propane-oxygen mixtures it is from 2.4 to $3.0 \mathrm{~mm}$, and with pentane-air mixtures it is about $3.6 \mathrm{~mm}$.

If all the variables except the size of the ourner tube are kept constant, the length of a side of the primary figure remains nearly constant while a smaller circumference results in a snaller number of sides, and vice versa.

Rotation of the polyhedral figure about its vertical axis is influenced by changes in either the composition or velocity of the mixture, or both. Rotation of the figure resulting from propane-air mixtures may be produced by changing the composition of the mixture toward the rich side, irrespective of whether a simultaneous change in the mixture velocity is an increase or a decrease. On the other hand, the direction of rotation of the five-sided figure obtained with propaneoxygen mixtures could be reversed by changing the velocity of the mixture, the composition remaining substantially constant. It was by this means that it was finally possible to maintain the figure stationary during the several minutes necessary for the exposure of autochrome plates.

Earlier in this paper a description has been given of a series of changes in the form of the primary figure (from a "cone" through a four-sided and a five-sided stage to a figure in rapid rotation), resulting from propane-air mixtures, which accompanied increases in the proportion of propane in the mixture. These increases in propane content were brought about by decreasing the air, with consequent decreases in the velocity of the mixture. 
The same changes in form may be produced in the same order with propane-oxygen mixtures burning on a burner of appropriate size, but contrary to expectation the changes are accomplished by increases in the oxygen content, with consequent increases in the velocity of the mixture.

\section{A POSSIBLE CAUSE OF ROTATION OF THE POLYHEDRAL FIGURE 11}

Little or nothing is known about the rotation of the polyhedral figure, but it is suspected that its cause may be traced to instability in the relation between the length of a side and the circumference of the burner tip.

On a given burner, the primary figure may have four sides with a given mixture composition and velocity. With some other composition and velocity the number of sides may change to five. This change in the number of sides must be the result of a decreased length of side, since the circumference of the burner tip is unchanged. With any intermediate condition the circumference divided by the length of a side is not a whole number, and the tendency toward symmetry in the polyhedral figure results in either a tendency for a ridge to flatten out and to stretch an inadequate number of sides over the whole circumference, or a tendency for a ridge to intrude itself into a side and distribute a larger number of sides over an inadequate circumference.

In either case the other ridges are displaced somewhat from their former positions, the figure reverts to the more stable of the two forms, and the process is rapidly repeated. If displacement of the ridges always occurs in the same direction, continuous rotation results in one direction or the other. If the displacement is not always in the same direction the rotation may be in either direction in a very haphazard manner, resulting in what has been described as an unsteady figure.

It must be borne in mind that if symmetrical polyhedral figures and figures which will rotate smoothly are to be obtained the burner tip must be circular and free from irregularities.

\section{POINTS OF SIMILARITY AND OF CONTRAST BETWEEN THE FLAMES}

There are some interesting and possibly significant points of general similarity and of difference to be noted between the various flames which have been described in this paper.

With propane-air mixtures the polyhedral primary figure can be obtained either with or without the exclusion of secondary air.

11 This rotation about a vertical axis is a rotation of the figure only, and does not involve any rotation of the gas stream. 
The hollow dark central core seems to be peculiar to acetylene, since it appears with acetylene-oxygen mixtures as well as with those of acetylene and air. In contrast with this, all oxygen-deficient flames of other hydrocarbons so far observed have shown the yellow stream of greater or less intensity rising from the tip of the primary figure, as in the case of the propane-oxygen flames.

The significance of the details of structure in these flames with respect to the various intermediate reactions taking place during combustion can be discussed intelligently only after the composition of the gases in the various parts of the flames has been determined.

Washington, February 6, 1929. 